\author{
NANO: Brief Reports and Reviews \\ Vol. 3, No. 3 (2008) 145-153 \\ DOI: http://dx.doi.org/10.1142/S1793292008000939
}

\title{
ATOMIC HYDROGEN-DRIVEN SIZE CONTROL OF CATALYTIC NANOPARTICLES FOR SINGLE-WALLED CARBON NANOTUBE GROWTH
}

\author{
HEE JIN JEONG*, , LAURENT EUDE*, MANOHARAN GOWTHAM*, \\ BERND MARQUARDT*, SUNG HUN LIM*, SHAIIMA ENOUZ*, COSTEL \\ SORIN COJOCARU*, KYUNG AH PARK ${ }^{\dagger}$, \\ YOUNG HEE LEE ${ }^{\dagger}$ and DIDIER PRIBAT* \\ *Laboratoire de Physique des Interfaces et des Couches Minces \\ Ecole Polytechnique, 91128, Palaiseau, France \\ ${ }^{\dagger}$ Carbon Nanotube Research Laboratory, Department of Physics \\ Center for Nanotubes and Nanostructured Composites \\ Sungkyunkwan Advanced Institute of Nanotechnology \\ Sungkyunkwan University, 440-746, Suwon, Korea
}

\section{ABSTRACT}

The effects of an atomic hydrogen $\left(\mathrm{H}_{\mathrm{at}}\right)$ pretreatment of the catalyst layer on the low temperature growth of single-walled carbon nanotubes (SWCNTs) have been investigated using a modified catalytic chemical vapor deposition system. Well-defined and isolated individual Fe nanoparticles as a catalyst are successfully formed on the defects with high trapping energy which are created on the $\mathrm{Al}_{2} \mathrm{O}_{3}$ surface by $\mathrm{H}_{\text {at }}$ pretreatment, yielding highly dense SWCNTs. The pretreatment mechanism of $\mathrm{H}_{\text {at }}$, compared to $\mathrm{H}_{2}$, is also discussed. It was also found that the quality of SWCNTs can be enhanced when $\mathrm{H}_{\mathrm{at}}$ is flowed with $\mathrm{CH}_{4}$ during nanotubes growth at low temperature. In this case, the undesired carbon products and defects on catalyst seeds and nanotube walls can be selectively removed by $H_{a t}$. Therefore it is essential to use $H_{a t}$ in the pretreatment stage for increasing catalytic activity and to keep the size of nanoparticles in the $\mathrm{nm}$ range. $\mathrm{H}_{\mathrm{at}}$ can also be employed in growth stage for enhancing SWCNTs quality and density at low temperature.

Keywords : Single-walled carbon nanotube; atomic hydrogen; catalytic nanoparticle; chemical vapor deposition.

\section{Introduction}

Since the first finding of single-walled carbon nanotubes (SWCNTs) in 1993, ${ }^{1}$ extensive research efforts have been carried out worldwide, in order to exploit their prominent physical and chemical properties. Various SWCNT-based devices such as field emission cathodes for displays, field effect transistors with breathtaking characteristics, gas sensors, and transparent conducting films have been successfully demonstrated. ${ }^{2-7}$ However, in spite of 
these outstanding demonstrations, a number of critical issues such as diameter and chirality control, uniformity, orientation, length, and crystalline quality of SWCNTs still remain unsolved. Also, lowtemperature synthesis of SWCNTs exhibiting a highly crystalline quality is a prerequisite or an additional advantage for most applications mentioned above.

There are several known processes ${ }^{8-10}$ and mechanisms ${ }^{11-14}$ for the growth of SWCNTs. In one of those, which uses chemical vapor deposition (CVD) and which is related to the vapor-liquidsolid (VLS) mechanism, ${ }^{15}$ SWCNTs are synthesized by catalytic decomposition of gaseous species on nanometer-sized metal particles. ${ }^{14}$ Actually, vaporsolid-solid (VSS) would probably be a more appropriate wording, since in situ transmission electron microscope studies show that, at least at moderate temperatures $\left(\sim 450^{\circ} \mathrm{C}-650^{\circ} \mathrm{C}\right)$, the catalyst particles remain crystalline during CNT growth. ${ }^{16-18}$ Because the VLS (or VSS) mechanism produces SWCNTs exhibiting diameters strongly correlated with the size of catalyst particles, ${ }^{14}$ it is of prime importance to precisely control the size and the distribution of those metal particles before growth. Hence, many techniques for controlling the preparation of catalyst particles in the nanometer range have been published so far. ${ }^{19-21}$ It is also absolutely necessary to avoid the coalescence of these nanometer-size particles (by surface diffusion) at the CVD growth temperature. If amorphous $\mathrm{Al}_{2} \mathrm{O}_{3}$ is used as a catalyst supporter, it is generally observed that thin and continuous catalyst metal films are broken up into well-defined and isolated individual nanoparticles when they are annealed at high temperature. ${ }^{20}$ The diffusion of metal atoms on the amorphous $\mathrm{Al}_{2} \mathrm{O}_{3}$ surface is reduced by defects with high trapping energy, thus inducing the pinning of metal clusters, at least up to a certain critical size. ${ }^{22}$ Therefore, the size and the diameter distribution of the nanoparticles are strongly governed by the density of the defects on the amorphous $\mathrm{Al}_{2} \mathrm{O}_{3}$ surface. ${ }^{23}$

Here, we study the formation of Fe nanoparticles on amorphous $\mathrm{Al}_{2} \mathrm{O}_{3}$ thin films and propose to use atomic hydrogen $\left(\mathrm{H}_{\mathrm{at}}\right)$ in order to create or stabilize surface defects with high trapping energy, that block the surface diffusion of Fe atoms and clusters at the SWCNT growth temperature. Atomic hydrogen has recently been used during SWCNT growth, ${ }^{24,25}$ but to the best of our knowledge, its effects on the size distribution of catalyst particles have never been reported. For the generation of $\mathrm{H}_{\mathrm{at}}$ and for the predecomposition of hydrocarbon gases, we have modified the standard CVD setup by adding two tungsten hot filaments on the gas inlets. Special care has been taken for optimizing the distance between the hot filaments and the sample, not to affect the sample temperature. We have found that catalyst nanoparticles with a narrow size distribution were produced when the sample was pretreated using $\mathrm{H}_{\mathrm{at}}$, yielding highly dense SWCNTs deposits. On the contrary, molecular hydrogen $\left(\mathrm{H}_{2}\right)$ pretreatment yields quite a wide size distribution of catalyst particles, resulting in low density of SWCNTs. We also report that the quality of SWCNTs can be enhanced by adding $\mathrm{H}_{\mathrm{at}}$ during growth, which removes the undesired carbon particles/amorphous deposits formed on catalyst seeds and tube walls.

\section{Experimental}

A $100 \mathrm{~nm}$ thick $\mathrm{Al}_{2} \mathrm{O}_{3}$ film, as a catalyst supporter, was sputter-deposited on Si substrates covered with a $400 \mathrm{~nm}$ thick thermal oxide. Transmission electron microscope (TEM) observation shows that this $\mathrm{Al}_{2} \mathrm{O}_{3}$ film was amorphous (see Fig. 1(a)). Fe thin film (as a catalyst) was then deposited at room temperature on top of the $\mathrm{Al}_{2} \mathrm{O}_{3}$ layer, to a nominal thickness of $0.5 \mathrm{~nm}$, using a deposition rate of $0.3 \AA / \mathrm{s}$. This corresponds to an amount of $\mathrm{Fe}$ between one and two monolayers, i.e., $\sim 10^{15}$ atoms $/ \mathrm{cm}^{2}$. After sputtering, the Fe film was featureless when observed with an atomic force microscope (AFM) (see Fig. 1(b)), indicating that the nucleation and agglomeration of nanoparticles do not take place during deposition, as opposed to $\mathrm{Au}^{22,23}$ The as-prepared catalysts were directly transferred without further treatment (such as oxidative calcinations) into the modified CVD reactor for $\mathrm{H}_{\text {at }}$ pretreatment and subsequent CNT growth. The schematic and photo images of the modified CVD system used in this study are shown in Fig. 1(c). Two hot tungsten filaments were placed $\mathbf{1 5 0} \mathrm{mm}$ upstream of the sample holder, in order to predecompose the hydrocarbon gases and molecular hydrogen before they reach the substrate. The filaments were thermally isolated using boron nitride cylinders, so that the heat convection between filaments is thought to be small, if not negligible. The filaments were operated at $\sim 1800^{\circ} \mathrm{C}$ for $\mathrm{H}_{2}$ and at $\sim 1600^{\circ} \mathrm{C}$ for $\mathrm{CH}_{4}$, values that were measured with an optical pyrometer. Since the substrate 


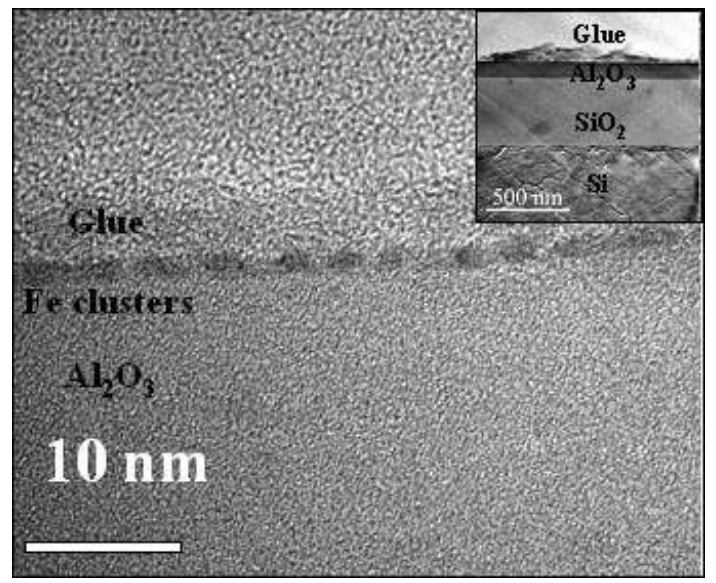

(a)

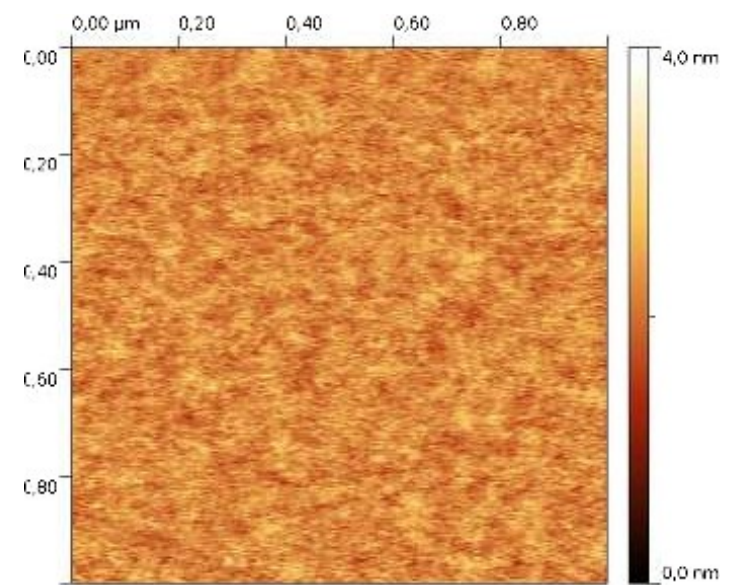

(b)

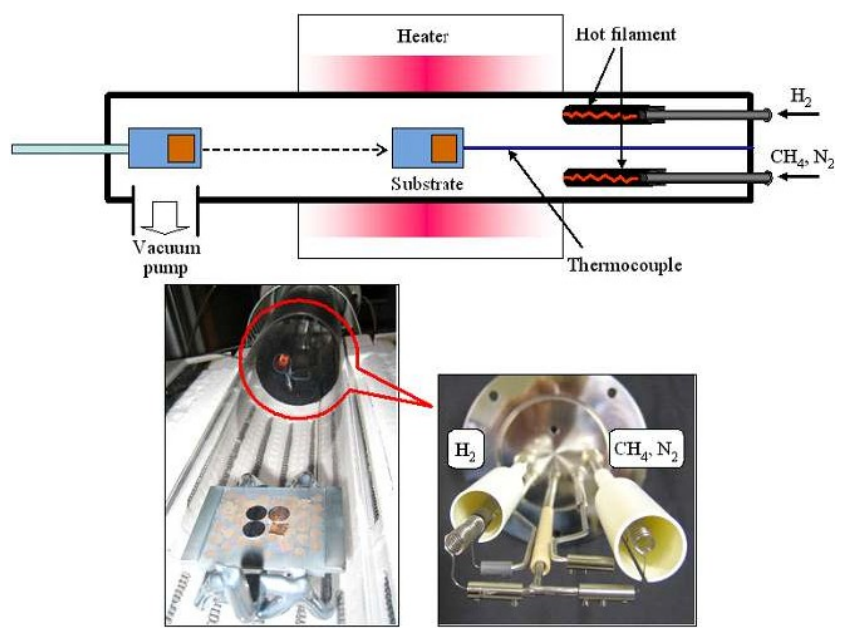

(c)

Fig. 1. (a) Cross-sectional TEM images of Fe clusters and $\mathrm{Al}_{2} \mathrm{O}_{3}$ layer. The Fe clusters are well defined and isolated on the surface of the $100 \mathrm{~nm}$ thick amorphous $\mathrm{Al}_{2} \mathrm{O}_{3}$ layer after $\mathrm{H}_{\text {at }}$ pretreatment for $10 \mathrm{~min}$ at $700^{\circ} \mathrm{C}$; (b) AFM image of o.5 $\mathrm{nm}$ thick Fe film before the $\mathrm{H}_{\text {at }}$ treatment; and (c) schematic and photo images of the modified CVD reactor used in this study.

heating (including the possible effect of the tungsten filaments) was automatically adjusted by a thermocouple situated at the same position as the substrate, the temperature was correctly controlled at the desired value during CNT growth. The samples were first placed at the end of the quartz tube, which is almost at room temperature, and rapidly pushed in the center region of the quartz tube using a stainless steel rod, once the temperature had stabilized at the desired value and once the $\mathrm{H}_{\mathrm{at}}$ had been activated by switching on the corresponding tungsten filament. We have used temperatures between $600^{\circ} \mathrm{C}$ and $800^{\circ} \mathrm{C}$ for the catalyst pretreatment and nanotube growth. Typically, $100 \mathrm{sccm}$ of $\mathrm{H}_{2}$ was flowed through the corresponding tungsten filaments for 5-40 min under a chamber pressure of 10 mbar to perform $\mathrm{H}_{\mathrm{at}}$ pretreatment. For SWCNT growth, $\mathrm{CH}_{4}$ was used, while $\mathrm{H}_{2}$ gas and its corresponding tungsten filament were switched off (unless otherwise stated). The methane gas was predecomposed with the help of the second tungsten filament, at a flow rate of $10 \mathrm{sccm}$ and under a chamber pressure of 100 mbar. After a growth time of $10 \mathrm{~min}, \mathrm{CH}_{4}$ and its corresponding tungsten filament were switched off, and the setup was allowed to cool down under a flow of $\mathrm{N}_{2}$ gas.

The sample morphology of the as-grown CNTs was observed using a Hitachi S48oo FEG highresolution scanning electron microscope (SEM). We used micro-Raman spectroscopy (Renishaw, Confocal Invia Reflex) with an excitation energy of 
$2.41 \mathrm{eV}$ (514 nm, $\mathrm{Ar}^{+}$laser) and Rayleigh line rejection filter with a spectral range of $100-3600 \mathrm{~cm}^{-1}$ for Stokes shift. The diameter and structure of the CNTs were also observed by high-resolution TEM (Philips $\mathrm{CM}_{30}$, $300 \mathrm{keV}$ ). The size distribution and uniformity of $\mathrm{Fe}$ nanoparticles after pretreatment with $\mathrm{H}_{2}$ and $\mathrm{H}_{\mathrm{at}}$ were investigated by AFM (Digital Instruments, Dimension 3100).

\section{Results and Discussion}

Figure 2 presents the Raman, SEM, and TEM images of SWCNTs grown at $800^{\circ} \mathrm{C}$ on Fe catalyst nanoparticles, which were converted from the $0.5 \mathrm{~nm}$ thick Fe films $\left(\sim 10^{15}\right.$ atoms $\left./ \mathrm{cm}^{2}\right)$, sputterdeposited on top of the $\mathrm{Al}_{2} \mathrm{O}_{3}$ layer, during a $5 \mathrm{~min}$ $\mathrm{H}_{\mathrm{at}}$ pretreatment before the growth. As shown in Fig. 2(a), the Raman spectrum exhibits one large peak at $1582 \mathrm{~cm}^{-1}$ (known as the $G$ band and associated with the $\mathrm{E}_{2 g}$ vibration mode of highly crystalline graphite) as well as a smaller peak at $1330 \mathrm{~cm}^{-1}$ (known as the D band, which originates from the carbonaceous particles and defects on the tube walls) ${ }^{26}$ Hence, the purity and the crystalline quality of the nanotubes can be qualitatively evaluated by the intensity ratio $\left(I_{D} / I_{G}\right)$ of these two peaks. The presence of SWCNTs is confirmed by the asymmetric shape of the $G$ band, which can be interpreted as the convolution of a $\mathrm{G}^{+}$band (vibrations along the nanotube axis) and a $\mathrm{G}^{-}$ one (vibrations along the circumferential direction), as well as by the occurrence of radial breathing modes (RBMs) at low wave numbers, which are associated with radial displacements of the carbon atoms. The $\mathrm{G}^{-}$band at $1550 \mathrm{~cm}^{-1}$ and RBMs at low frequency (as observed in the insets of Fig. 2(a)) clearly indicate the existence of SWCNTs in this sample. As shown in the inset, the RBM peaks are quite narrow with a very sharp peak located at $178 \mathrm{~cm}^{-1}$, indicating nanotubes of $1.39 \mathrm{~nm}$ in diameter (remember that the RBM frequency is inversely proportional to the nanotube diameter, i.e., $\left.\omega\left(\mathrm{cm}^{-1}\right)=234 / d(\mathrm{~nm})+10\right) .{ }^{27}$ Therefore, assuming a VLS (or VSS)-type growth mechanism, we can infer that the Fe film was converted into uniformly distributed nanoparticles during the $\mathrm{H}_{\mathrm{at}}$ pretreatment step, yielding highly dense SWCNTs with a narrow diameter distribution. This is confirmed again by Raman spectrum taken from a $633 \mathrm{~nm}$ He-Ne laser, as shown in Fig. 2(f). We also note that the fast heating rate of the catalyst film (by pushing the substrate into the heat-stabilized furnace zone) helps preventing the aggregation of

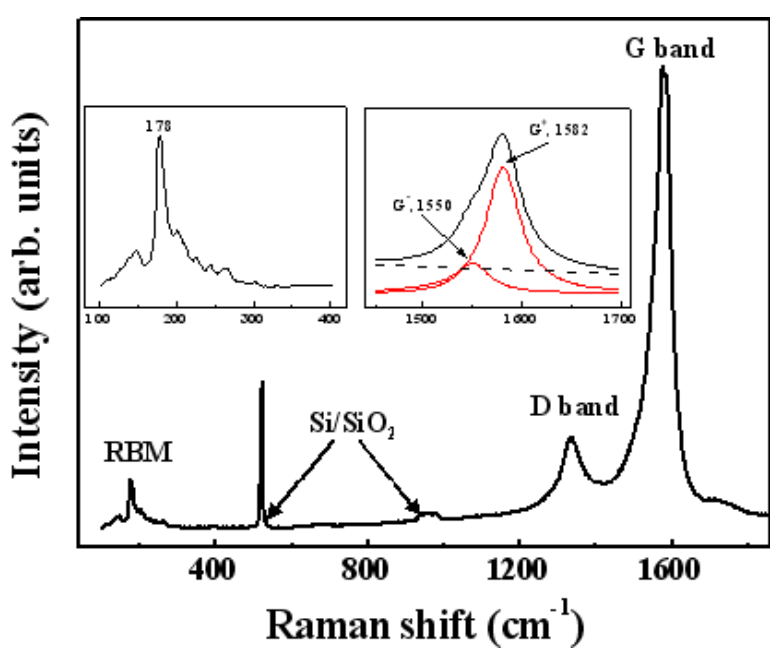

(a)

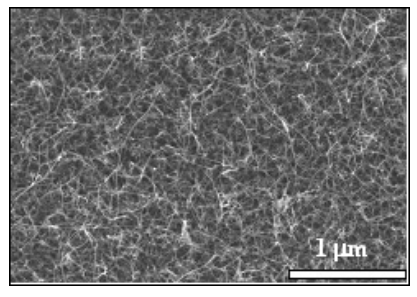

(b)

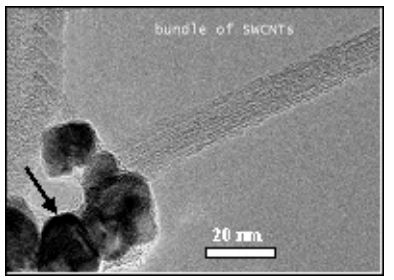

(d)

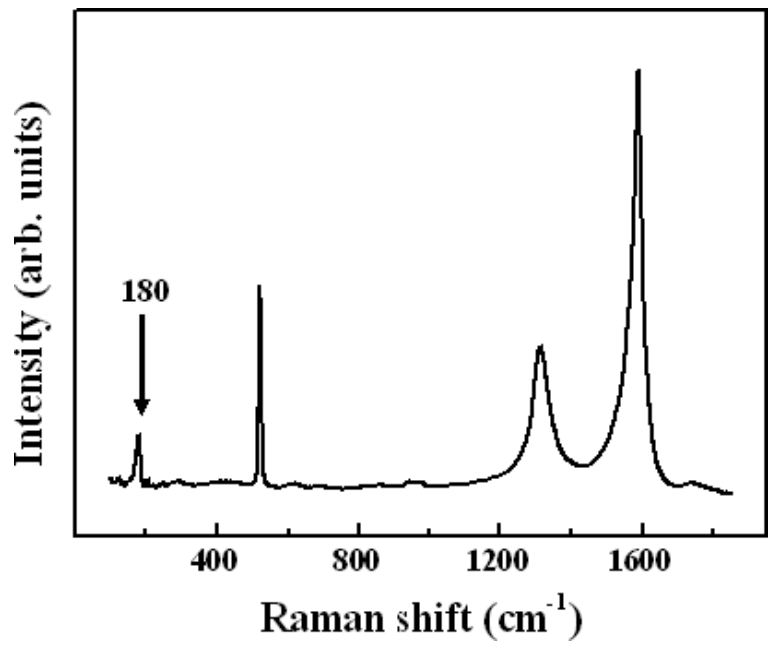

(f)

Fig. 2. (a) Raman spectrum (514 nm), (b) SEM, (c)-(e) TEM images, and (f) Raman spectrum (633 nm) of SWCNTs grown at $800^{\circ} \mathrm{C}$ after a 5 min $\mathrm{H}_{\text {at }}$ pretreatment. Insets in (a) show an enlarged view of the RBMs (left-hand side) and the deconvolution of the $\mathrm{G}$ band (right-hand side). 
the catalyst nanoparticles. Actually, when the samples were first loaded in the central area of the (cold) furnace and heated to the growth temperature (under flowing $\mathrm{N}_{2}$ or $\mathrm{H}_{2}$, but without $\mathrm{H}_{\mathrm{at}}$ ), no SWCNTs were grown in any case, whether or not the $\mathrm{H}_{\text {at }}$ pretreatment was performed (before growth at the chosen growth temperature), because of catalyst aggregation to large clusters during temperature ramping up, in the absence of $\mathrm{H}_{\mathrm{at}}$.

In the meantime, the pretreatment conditions for optimal SWCNTs growth have to be tuned as a function of the desired growth temperature, i.e., a longer pretreatment time is needed at lower temperature $\left(10 \mathrm{~min}\right.$ at $700^{\circ} \mathrm{C}$ and $20 \mathrm{~min}$ at $600^{\circ} \mathrm{C}$ ). This will be discussed later. Figure 2(b) shows the SEM image of as-grown SWCNTs. The nanotubes are quite straight and long without significant bending on the walls, indicating a highly crystalline quality. This is consistent with the Raman results shown in Fig. 2(a) and the TEM analysis of SWCNTs presented in Figs. 2(c)-2(e). Amorphous carbon particles are hardly observed on the nanotube walls. Most of the SWCNTs are bundled due to strong van der Waals interaction. ${ }^{9}$

The effect of the $\mathrm{H}_{\mathrm{at}}$ pretreatment on the growth of SWCNTs at $700^{\circ} \mathrm{C}$ was equally investigated, as depicted in Fig. 3. Figures 3(a)-3(c) show the Raman spectra of as-grown SWCNTs with

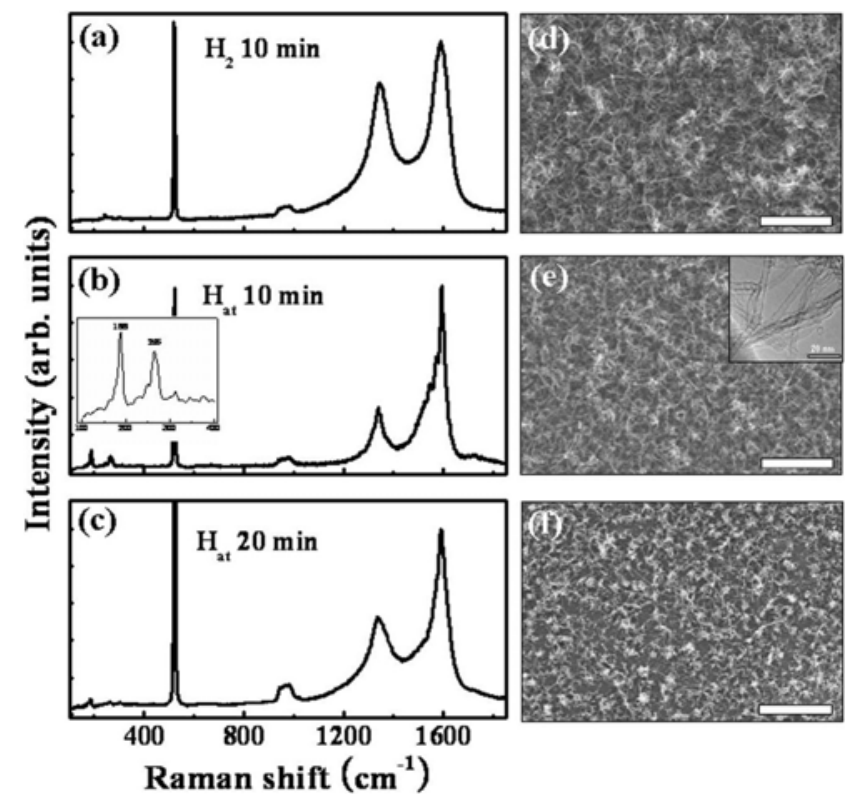

Fig. 3. (a)-(c) Raman spectra, (d)-(f) SEM, and TEM images of SWCNTs grown at $700^{\circ} \mathrm{C}$ after different pretreatment conditions. The scale bars in SEM images are $\mathbf{1} \mu \mathrm{m}$. Inset in (b) show an enlarged view of the RBMs. Scale bar in the inset of (e) is $20 \mathrm{~nm}$. different pretreatment processes. When the samples were treated using $\mathrm{H}_{2}$ only, no significant RBM peaks were observed (Fig. 3(a)) which means that most of the CNTs are multi-walled. Besides, large intensity ratio of $D / G$ indicates that the quality of nanotubes is extremely poor, which is also confirmed by the SEM image of Fig. 3(d). Nanotubes are severely bent and curled on the substrate due to large defect densities on their walls. However, when the samples were pretreated for 10 min using $\mathrm{H}_{\text {at }}$, SWCNTs exhibiting two strong RBM peaks at 188 and $265 \mathrm{~cm}^{-1}$ (corresponding to diameters of 1.3 and $0.9 \mathrm{~nm}$ ), and low D band intensity were observed (see Fig. 3(b)). From the SEM and TEM images in Fig. 3(e), we can observe that straight and long SWCNTs with high crystalline quality were grown on the substrate, which contribute to the low D band in the Raman spectrum. Although some double-walled CNTs with large inner diameters $(2.8-3.5 \mathrm{~nm})$ were also observed from the TEM image, it was impossible to measure their diameter by using the Raman RBMs due to the limitation of the notch filter in our setup. When the $\mathrm{H}_{\mathrm{at}}$ pretreatment time was increased to $20 \mathrm{~min}$, large diameter of nanotubes with poor quality was observed in Raman and SEM images (see Figs. 3(c) and 3(f)).

At this point, we would like to emphasize that some kind of treatment is always necessary before CNT growth, in order to prepare/shape/purify catalyst nanoparticles. ${ }^{28,29}$ For instance, catalysts prepared by a chemical method should be oxidized first, because they contain various organic pollutions that bond with catalyst atoms and poison them. A hydrogen reduction step is therefore necessary prior to CNT growth. ${ }^{14,21}$ Also, the pretreatment will lead to a size reduction of the catalytic particles by an etching/evaporation process. ${ }^{30}$ In our situation, we need to fragment the continuous Fe thin film into small catalyst clusters which are necessary to promote CNT nucleation and growth. The driving force for cluster formation is believed to be the decrease of surface energy of the $\mathrm{Fe}$ thin film. Actually, at the sputtering temperature ( $\sim$ room temperature), there is not enough thermal energy to promote surface diffusion, and the $\mathrm{Fe}$ atoms just "stick" where they impinge on the $\mathrm{Al}_{2} \mathrm{O}_{3}$ surface, yielding a quasi-continuous deposit. At high temperature, where surface diffusion is activated, the system gains energy by minimizing the total surface of the catalyst deposit and by maximizing the $\mathrm{Al}_{2} \mathrm{O}_{3}$ surface with lower energy. This can be explained as follows: when Fe is deposited, the surface of the deposit exhibits several dangling 
bonds per atom, corresponding to a typical surface defect density of several $10^{14} / \mathrm{cm}^{2}$ and even higher. These defects are passivated by oxygen atoms as the films are exposed to air (or to a bad vacuum), thus reducing the high surface energy. At the annealing temperature and under a reducing atmosphere, oxygen is rapidly removed, converting the Fe surface back to high energy. On the other hand, the defect density on the $\mathrm{Al}_{2} \mathrm{O}_{3}$ surface is typically of the order of several $10^{12} / \mathrm{cm}^{2},{ }^{22}$ i.e., $\sim$ two orders of magnitude lower than that of the Fe surface. In other words, if $\gamma_{i s}$ are the surface energies and $\gamma^{*}$ the interface energy, $\gamma_{\mathrm{Fe}}+\gamma^{*}>\gamma_{\mathrm{Al}_{2} \mathrm{O}_{3}}$ and the system gains energy by minimizing the Fe surface, converting the continuous film into small islands, which are nucleated on the surface defects of $\mathrm{Al}_{2} \mathrm{O}_{3}{ }^{22}$ However, if thermodynamics is allowed to proceed, then the Fe clusters tend to grow larger, building lowenergy crystalline facets. The trick is therefore to control surface diffusion over short distances $(\sim$ few $\mathrm{nm})$, in order to keep a small Fe cluster size.

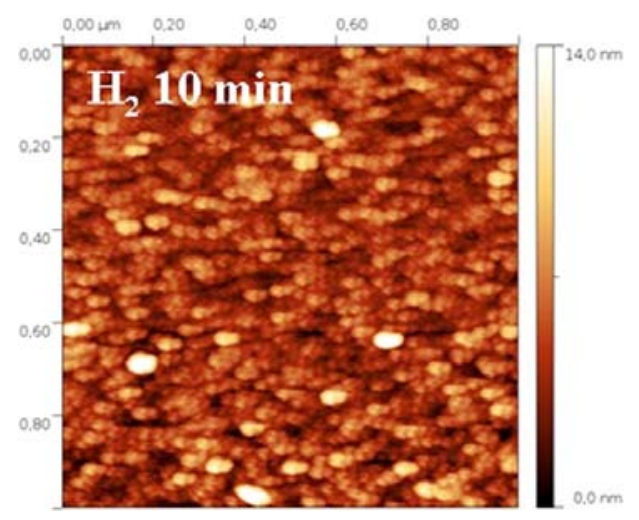

(a)

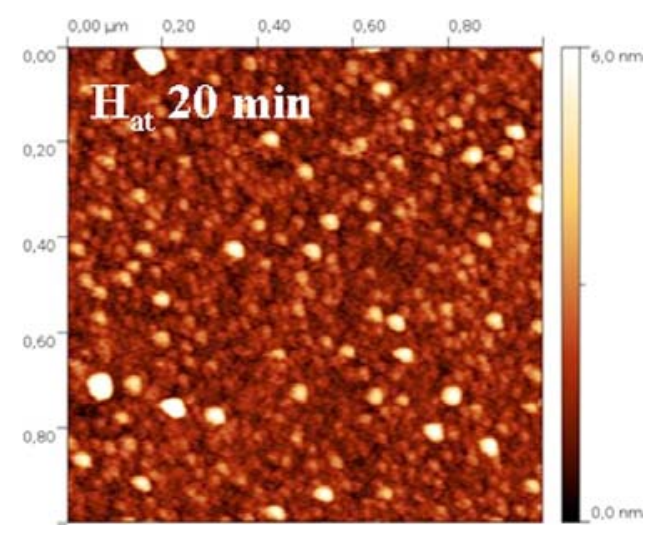

(c)
The surface morphology and size distribution of catalyst particles pretreated with $\mathrm{H}_{2}$ and $\mathrm{H}_{\mathrm{at}}$ at $700^{\circ} \mathrm{C}$ are shown in Fig. 4. Although an $\mathrm{Al}_{2} \mathrm{O}_{3}$ layer was employed as a catalyst supporter, there are still (few) large clusters in all samples, as observed in the (AFM) images, Figs. 4(a)-4(c). They probably originate from the coalescence of smaller clusters due to surface defects with a low pinning energy, ${ }^{22}$ that could be related to local impurities. The Gaussian shapes of size distributions of catalyst particles, as shown in Fig. 4(d), were extracted from $2 \mathrm{D}$ AFM height distribution using data analysis software (Gwyddion version 2.9). We note that a very narrow size distribution of catalyst particles with a maximum frequency at $1.3 \mathrm{~nm}$ is obtained when the sample is pretreated for 10 min with $H_{a t}$, which is also evidenced by a TEM image as shown in Fig. 1(a). This particle size is very close to the diameter of SWCNTs grown at $700^{\circ} \mathrm{C}$ (see Fig. 3(b)), which suggests a VLS-type growth mechanism. ${ }^{14}$ We believe that highly active

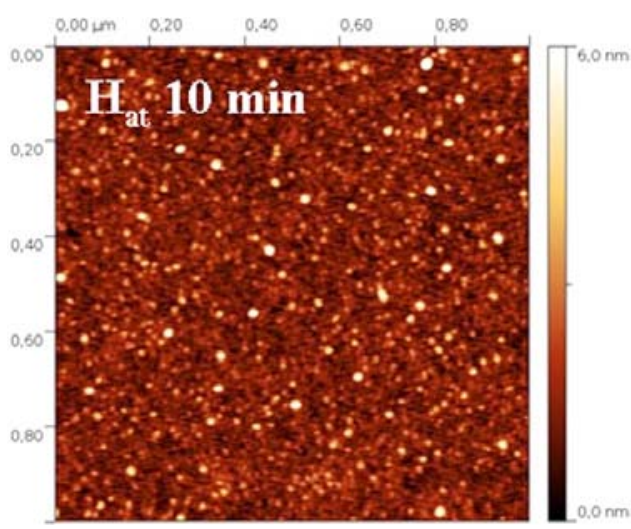

(b)

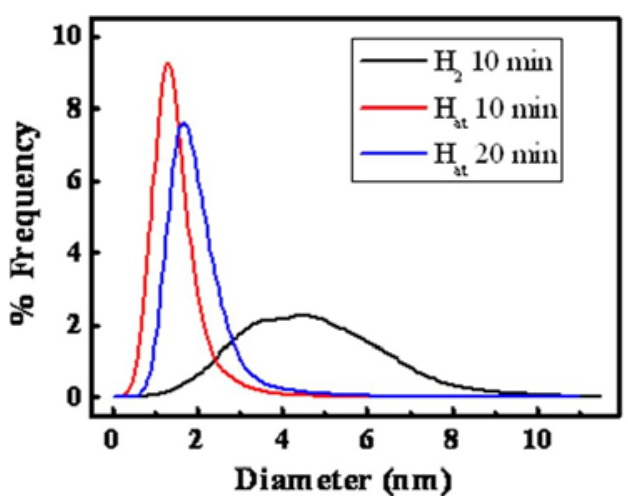

(d)

Fig. 4. AFM images of Fe catalyst particles after pretreatment at $700^{\circ} \mathrm{C}$ using (a) $\mathrm{H}_{2}$ for 10 min, (b) $\mathrm{H}_{\text {at }}$ for $10 \mathrm{~min}$, (c) $\mathrm{H}_{a t}$ for $20 \mathrm{~min}$, and (d) the corresponding size distributions. 
$\mathrm{H}_{\text {at }}$ creates and stabilizes defects with a high trapping energy on the $\mathrm{Al}_{2} \mathrm{O}_{3}$ surface, thus preventing surface diffusion from taking place and increasing the pinning of catalyst clusters. Actually, assuming a totally uniform distribution of $\mathbf{1 . 3} \mathrm{nm}$ diameter clusters (i.e., containing each $\sim 50 \mathrm{Fe}$ atoms) and assuming that each cluster is pinned on a surface defect, we obtain a surface defect density of $\sim(1 / 50) \times 10^{15}$ atoms $/ \mathrm{cm}^{2}=2 \times 10^{13} / \mathrm{cm}^{2}$, about 10 times higher than that of the as-sputtered $\mathrm{Al}_{2} \mathrm{O}_{3}$ surface. ${ }^{22}$ Although this rough estimate is probably on the high side (on a square lattice, it would correspond to a defect every $2.23 \mathrm{~nm}$, leaving less than $1 \mathrm{~nm}$ between clusters), it shows that the $\mathrm{H}_{\mathrm{at}}$ treatment increases the $\mathrm{Al}_{2} \mathrm{O}_{3}$ surface defect density, thus highly contributing to the inhibition of surface diffusion of $\mathrm{Fe}$ atoms and clusters. On the contrary, when $\mathrm{H}_{2}$ was used, the size distribution of the nanoparticles became considerably broader. These results are in good agreement with the SWCNTs growth behavior, as shown previously in Fig. 3. This means that $\mathrm{H}_{2}$ is not efficient to create defects with high trapping energy on the $\mathrm{Al}_{2} \mathrm{O}_{3}$ surface, and thus the surface diffusion of the $\mathrm{Fe}$ atoms/catalyst particles is not suppressed, resulting in the aggregation of the nanoparticles. When $\mathrm{H}_{\mathrm{at}}$ pretreatment was increased up to $20 \mathrm{~min}$, however, the size distribution was slightly shifted toward larger diameters, probably due to some catalyst aggregation even in the $\mathrm{H}_{a t}$ atmosphere. This can be explained by the very high density of defects on the surface of $\mathrm{Al}_{2} \mathrm{O}_{3}$, inducing some coalescence of the catalyst nanoparticles. ${ }^{23}$ Actually, if the average distance between defects is below the average diameter of the catalyst nanoparticles, some coalescence is due to occur.

Figure 5 shows Raman and SEM images of SWCNTs grown at $600^{\circ} \mathrm{C}$ with $\mathrm{H}_{\text {at }}$ pretreatment durations ranging from 10 to $40 \mathrm{~min}$. No significant differences at D band of Raman spectra in Fig. 5(a) are observed, indicating that the quality of nanotubes does not change severely. In the RBMs, however, the intensity of the main peak near $245 \mathrm{~cm}^{-1}$, which corresponds to SWCNTs of $\mathbf{1 . 0} \mathrm{nm}$ in diameter, varies with pretreatment time. The maximum intensity of this peak is obtained when the sample is pretreated for 20 min using $\mathrm{H}_{\text {at }}$ (inset of Fig. 5(a)). This is attributed to uniformly distributed catalyst particles with small diameters.

It is noteworthy that the optimum pretreatment time varies with the nanotubes growth temperature, i.e., $5 \mathrm{~min}$ at $800^{\circ} \mathrm{C}, 10 \mathrm{~min}$ at $700^{\circ} \mathrm{C}$, and
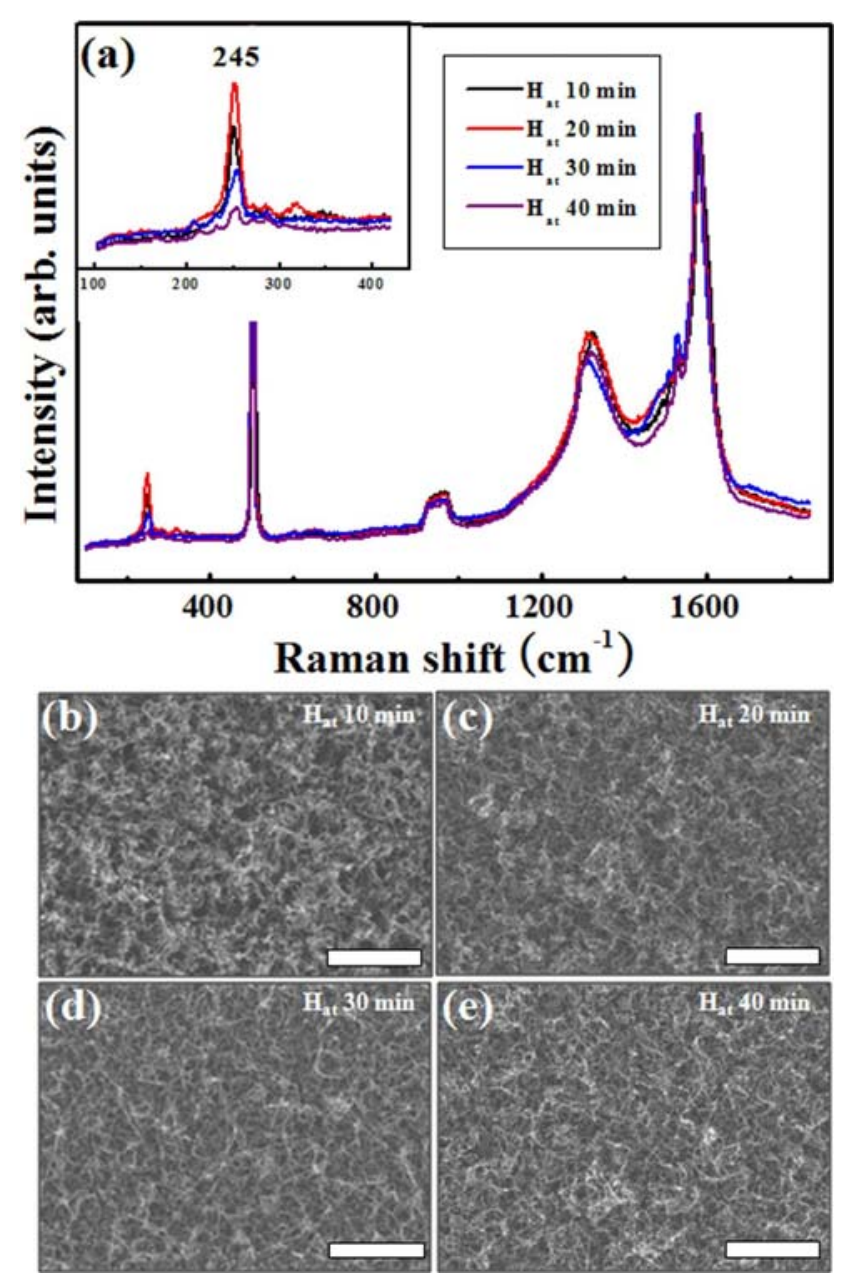

Fig. 5. (a) Raman spectra and (b)-(e) SEM images of SWCNTs grown at $600^{\circ} \mathrm{C}$ after different $\mathrm{H}_{\text {at }}$ pretreatment times. The scale bars in the SEM images are $1 \mu \mathrm{m}$.

20 min at $600^{\circ} \mathrm{C}$, reflecting the fact that the defect creation rate is a thermally activated phenomenon. Of course, an added parameter influencing the pretreatment time might be the recombination rate of $\mathrm{H}_{\mathrm{at}}$ which also varies with temperature. Therefore, $\mathrm{H}_{\text {at }}$ pretreatment conditions such as time, hot filament power, and gas flow rate should be optimized according to the sample temperature.

In order to investigate the $\mathrm{H}_{\text {at }}$ effect during growth at low temperature, $\mathrm{H}_{2}$ and $\mathrm{CH}_{4}$ were flowed through their respective hot filaments during growth. Figure 6 shows the Raman spectra of SWCNTs grown with and without $\mathrm{H}_{\mathrm{at}}$ at $600^{\circ} \mathrm{C}$. In this case, $\mathrm{H}_{\mathrm{at}}$ pretreatment was performed for $20 \mathrm{~min}$ on both samples, and the same catalyst size distribution is expected. This is evidenced by the same SWCNTs diameters estimated from RBM peak positions in both samples. It has been 


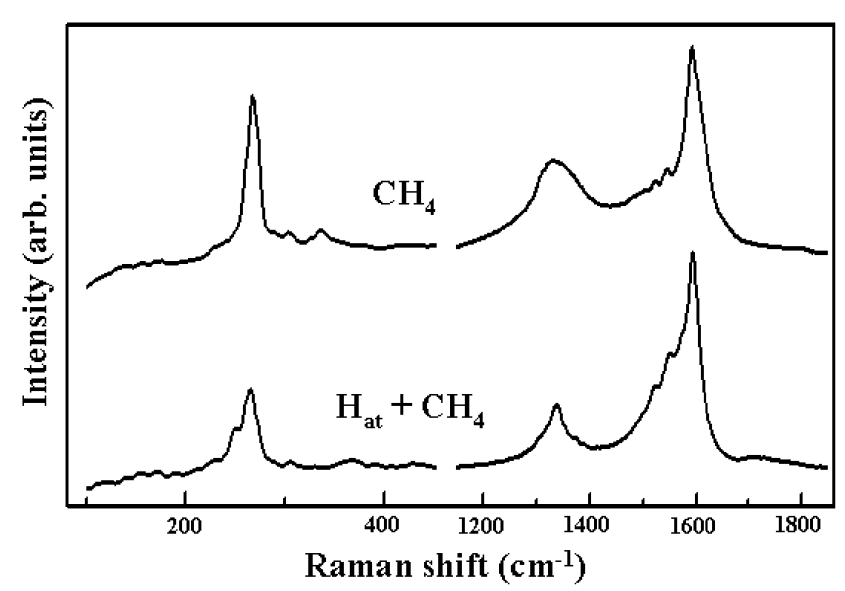

Fig. 6. Raman spectra of SWCNTs grown with the mixture of $\mathrm{H}_{a}+\mathrm{CH}_{4}$ and with $\mathrm{CH}_{4}$ alone at $600^{\circ} \mathrm{C}$.

previously reported that the presence of $\mathrm{H}_{\mathrm{at}}$ is essential for both nucleation and continued growth of SWCNT, ${ }^{25}$ because $\mathrm{H}_{\text {at }}$ can etch amorphous carbon deposits formed on catalyst seeds. Indeed, the $\mathrm{D}$ band intensity of nanotubes grown with the mixture of $\mathrm{H}_{\mathrm{at}}+\mathrm{CH}_{4}$ is intensively decreased compared to the case of $\mathrm{CH}_{4}$ alone (see Fig. 6).

Actually, the use of $\mathrm{H}_{\mathrm{at}}$ during CNT synthesis is quite controversial, since a high concentration of reactive $\mathrm{H}_{\mathrm{at}}$ will etch not only the amorphous carbon deposits, but also the small diameter SWCNTs, ${ }^{31}$ of technological interest, e.g., device fabrication. ${ }^{32}$ This etching effect is reflected in our experiments by the slight intensity decrease of RBMs in the $\mathrm{H}_{\mathrm{at}}+\mathrm{CH}_{4}$ grown sample, as shown in Fig. 6. Therefore, for the growth of SWCNTs with highly crystalline quality and high density at low temperature, the concentration of $\mathrm{H}_{\mathrm{at}}$ should be carefully optimized to selectively etch the undesired carbon products without damaging the SWCNTs.

\section{Conclusion}

We have investigated the effects of $\mathrm{H}_{\text {at }}$ pretreatment on $\mathrm{Al}_{2} \mathrm{O}_{3}$-supported thin catalyst films for low-temperature SWCNT growth using a modified catalytic CVD system. The size and distribution of Fe catalytic nanoparticles are successfully controlled by the density of the defects, which can be created on the $\mathrm{Al}_{2} \mathrm{O}_{3}$ surface by the $\mathrm{H}_{\text {at }}$ pretreatment. Defects with high trapping energy can suppress the surface diffusion and increase the pinning effect of the nanoclusters, resulting in welldefined and isolated catalytic nanoparticles. It was also found that the quality of SWCNTs can be enhanced when $\mathrm{H}_{\text {at }}$ is flowed with $\mathrm{CH}_{4}$ during nanotubes growth at low temperature. In this case, the undesired carbon products and defects on catalyst seeds and nanotube walls can be selectively removed by $\mathrm{H}_{\mathrm{at}}$. Therefore, it is essential to use $\mathrm{H}_{\mathrm{at}}$ in pretreatment stage for increasing catalytic activity and to keep the size of nanoparticles in the nanometer range. $\mathrm{H}_{\mathrm{at}}$ can also be employed in growth stage for enhancing SWCNTs quality and density at low temperature.

\section{Acknowledgments}

This work was supported by the EC contract CANDICE (FP 6) and by the ANR contract NANORESEAUX. H. J. Jeong is partially supported by the Korea Research Foundation Grant funded by the Korean Government (MOEHRD) (KRF-2005-214Cooo23).

\section{References}

1. S. Iijima and T. Ichihashi, Nature 363, 603 (1993).

2. W. B. Choi, D. S. Chung, J. H. Kang, H. Y. Kim, Y. W. Jin, I. T. Han, Y. H. Lee, J. E. Jung, N. S. Lee, G. S. Park and J. M. Kim, Appl. Phys. Lett. 75, 3129 (1999).

3. S. J. Tans, A. R. M. Verschueren and C. Dekker, Nature 393, 49 (1998).

4. A. Javey, H. Kim, M. Brink, Q. Wang, A. Ural, J. Guo, P. McIntyre, P. McEuen, M. Lundstrom and H. Dai, Nature Mater. 1, 241 (2002).

5. J. Kong, N. R. Franklin, C. Zhou, M. G. Chapline, S. Peng, K. Cho and H. Dai, Science 287, 622 (2000).

6. Z. C. Wu, Z. Chen, X. Du, J. M. Logan, J. Sippel, M. Nikolou, K. Kamaras, J. R. Reynolds, D. B. Tanner, A. F. Herbard and A. G. Rinzler, Science 305, 1273 (2004).

7. H.Z. Geng, K. K. Kim, K. P. So, Y. S. Lee, Y. Chang and Y. H. Lee, J. Am. Chem. Soc. 129, 7758 (2007).

8. D. S. Bethune, C. H. Klang, M. S. de Vries, G. Gorman, R. Savoy, J. Vazquez and R. Beyers, Nature 363, 605 (1993).

9. A. Thess, R. Lee, P. Nikolaev, H. Dai, P. Petit, J. Robert, C. Xu, Y. H. Lee, S. G. Kim, A. G. Rinzler, D. T. Colbert, G. E. Scuseria, D. Tománek, J. E. Fischer and R. E. Smalley, Science 273, 483 (1996).

10. H. M. Cheng, F. Li, G. Su, H. Y. Pan, L. L. He, X. Sun and M. S. Dresselhaus, Appl. Phys. Lett. 72, 3282 (1998).

11. J. Gavillet, A. Loiseau, C. Journet, F. Willaime, F. Ducastelle and J. C. Charlier, Phys. Rev. Lett. 87, 275504 (2001). 
12. Y. H. Lee, S. G. Kim and D. Tománek, Phys. Rev. Lett. 78, 2393 (1997).

13. A. Maiti, C. J. Brabec, C. Roland and J. Bernholc, Phys. Rev. B 52, 14850 (1995).

14. R. E. Smalley, Y. Li, V. C. Moore, K. Price, R. Colorado Jr, H. K. Schmidt, R. H. Hauge, A. R. Barron and J. M. Tour, J. Am. Chem. Soc. 128, 15824 (2006).

15. R. S. Wagner and W. C. Ellis, Appl. Phys. Lett. 4, 89 (1964).

16. S. Helveg, C. López-Cartes, J. Sehested, P. L. Hansen, B. S. Clausen, J. R. Rostrup-Nielsen, F. Abild-Pedersen and J. K. Nørskov, Nature 427, 426 (2004).

17. R. Sharma and Z. Iqbal, Appl. Phys. Lett. 84, 990 (2004).

18. M. Lin, J. P. Y. Tan, C. Boothroyd, K. P. Loh, E. S. Tok and Y. L. Foo, Nano Lett. 6, 449 (2006).

19. Y. Y. Wang, S. Gupta and R. J. Nemanich, Appl. Phys. Lett. 85, 2601 (2004).

20. T. Yamada, T. Namai, K. Hata, D. N. Futaba, K. Mizuno, J. Fan, M. Yudasaka, M. Yumura and S. Iijima, Nature Nanotechnol. 1, 131 (2006).

21. S. J. Kang, C. Kocabas, T. Ozel, M. Shim, N. Pimparkar, M. A. Alam, S. V. Rotkin and J. A. Rogers, Nature Nanotechnol. 2, 230 (2007).

22. J. Carrey, J. L. Maurice, F. Petroff and A. Vaurès, Phys. Rev. Lett. 86, 4600 (2001).

23. N. Lidgi-Guigui, P. Seneor, F. Nguyen Van Dau, A. Friederich, A. Vaurès and C. Deranlot, Appl. Phys. Lett. 90, 233101 (2007).
24. Y. Q. Xu, E. Flor, M. J. Kim, B. Hamadani, H. Schmidt, R. E. Smalley and R. H. Hauge, J. Am. Chem. Soc. 128, 656o (2006).

25. Y. Q. Xu, E. Flor, H. Schmidt, R. E. Smalley and R. H. Hauge, Appl. Phys. Lett. 89, 123116 (2006).

26. A. M. Rao, E. Richter, S. Bandow, B. Chase, P. C. Eklund, K. A. Williams, S. Fang, K. R. Subbaswamy, M. Menon, A. Thess, R. E. Smalley, G. Dresselhaus and M. S. Dresselhaus, Science 275, 187 (1997).

27. M. Milnera, J. Kurti, M. Hulman and H. Kuzmany, Phys. Rev. Lett. 84, 1324 (2000).

28. Z. F. Ren, Z. P. Huang, J. W. Xu, J. H. Wang, P. Bush, M. P. Siegal and P. N. Provencio, Science 282, 1105 (1998).

29. S. Bhaviripudi, E. Mile, S. A. Steiner, III, A. T. Zare, M. S. Dresselhaus, A. M. Belcher and J. Kong, J. Am. Chem. Soc. 129, 1516 (2007).

30. D. Takagi, Y. Homma, H. Hibino, S. Suzuki and Y. Kobayashi, Nano Lett. 6, 2642 (2007).

31. G. Zhang, D. Mann, L. Zhang, A. Javey, Y. Li, E. Yenilmez, Q. Wang, J. P. McVittie, Y. Nishi, J. Gibbons and H. Dai, Proc. Natl. Acad. Sci. 102, 16141 (2005).

32. H. Dai, A. Javey, E. Pop, D. Mann, W. Kim and Y. Lu, Nano 1, 1 (2006). 